\title{
PENGARUH PELATIHAN KESELAMATAN PASIEN DENGAN METODE CERAMAH TERHADAP PEMAHAMAN PERAWAT MENGENAI PENERAPAN SASARAN KESELAMATAN PASIEN DI RS PMC PEKANBARU
}

\author{
Awaliyah Ulfah Ayudytha Ezdha ${ }^{1}$, Silvia Nora Anggreini ${ }^{2}$, Dwi Elka Fitri ${ }^{3}$ \\ ${ }^{1,2,3}$ STIKes Pekanbaru Medical Center, Pekanbaru Riau \\ Email :dhita_87@yahoo.com
}

Diterima: September 2018, diterbitkan: Desember 2018

\begin{abstract}
Quality development in hospitals has led to efforts to improve quality oriented to patient safety. Patient safety is a variable to measure and evaluate the quality of nursing services that have an impact on health services. The purpose of this study was to determine the effectiveness of patient safety training with the lecture method in improving nurses' understanding of the application of patient safety goals. The research method used the quantitative method with one group design. This research was carried out at Pekanbaru Medical Center Hospital with a sample of research that were 30 nurses who served in the hospital, according to the inclusion criteria. The results showed that the mean value of nurses' understanding of the patient's safety culture before the training with the lecture method was 52.83 with a standard deviation of 7.742. The mean value of nurses' understanding of the application of patient safety after training with the lecture method was 67.47 with a standard deviation of 8.320. The results of the dependent $t$ test where $p$ value $=0,000$ are smaller than the alpha value ( $p<0.05)$. This means that there is a significant influence between the mean value of nurses' understanding of the application of patient safety before and after training with the lecture method. The results of this study are expected in addition to increasing the understanding of nurses as well as the hospital can apply the most appropriate method so that the goals of patient safety goals, namely service quality can be achieved.
\end{abstract}

Keywords: Lecture, Patient Safety, Training

\begin{abstract}
Abstrak
Pengembangan mutu di rumah sakit telah mengarah pada upaya peningkatan mutu yang berorientasi pada keselamatan pasien. Keselamatan pasien (patient safety) merupakan suatu variabel untuk mengukur dan mengevaluasi kualitas pelayanan keperawatan yang berdampak terhadap pelayanan kesehatan. Tujuan dari penelitian ini adalah untuk mengetahui efektifitas pelatihan keselamatan pasien dengan metode ceramah dalam meningkatkan pemahaman perawat tentang penerapan sasaran keselamatan pasien. Metode penelitian yang digunakan metode kuantitatif dengan one grup. Penelitian ini di laksanakan di Rumah Sakit Pekanbaru Medical Center dengan sampel penelitian adalah perawat yang bertugas di RS tersebut yaitu sebanyak 30 orang sesuai sesuai kriteria inklusi. Hasil penelitian didapatkan mean nilai pemahaman perawat tentang budaya keselamatan pasien sebelum dilakukan pelatihan dengan metode ceramah adalah 52,83 dengan standar deviasi 7,742. Mean nilai pemahaman perawat tentang penerapan keselamatan pasien setelah dilakukan pelatihan dengan metode ceramah adalah 67,47 dengan standar deviasi 8,320. Hasil uji t dependent dimana $p$ value $=0.000$ lebih kecil daripada nilai alpha $(p<0,05)$. Hal ini berarti ada pengaruh yang signifikan antara mean nilai pemahaman perawat tentang penerapan keselamatan pasien sebelum dan setelah dilakukan pelatihan dengan metode ceramah. Hasil dari penelitian ini di harapkan selain peningkatan pamahaman perawat juga pihak RS dapat menerapkan metode yang paling tepat sehingga tujuan dari sasaran keselamatan pasien yaitu mutu pelayanan dapat tercapai.
\end{abstract}

Kata Kunci: Ceramah, Keselamatan pasien, Pelatihan 


\section{PENDAHULUAN}

Keselamatan pasien (patient safety) merupakan suatu variabel untuk mengukur dan mengevaluasi kualitas pelayanan keperawatan yang berdampak terhadap pelayanan kesehatan. Program keselamatan pasien bertujuan menurunkan angka Kejadian Tidak Diharapkan (KTD) yang sering terjadi pada pasien selama dirawat di rumah sakit sehingga sangat merugikan baik pasien sendiri dan pihak rumah sakit. KTD bisa disebabkan oleh berbagai faktor antara lain beban kerja perawat yang cukup tinggi, alur komunikasi yang kurang tepat, penggunaan sarana kurang tepat dan lain sebagainya (Nursalam, 2011).

Di Indonesia sendiri kejadian tentang KTD apalagi Nyaris Cedera (near miss) masih langka, namun dilain pihak terjadi peningkatan tuduhan malpraktik yang belum tentu sesuai dengan pembuktian akhir (DepKes, 2008). Kejadian di Jawa dengan jumlah penduduk sebanyak 112 juta penduduk yang mengalami kejadian merugikan sebanyak 4.544 .711 orang yang dapat dicegah sebanyak 2.847.288 orang, cacat permanen sebanyak 337.000 orang, kematian sebanyak 121.000 orang dengan beban ekonomi sebesar 495 M. Prevalensi kejadian medis yang merugikan pasien di Jawa Tengah dan DIY menurut sebuah hasil penelitian adalah sebesar 1,8\% - 88,9\% (Sunaryo, 2009).

Untuk meminimalisir kejadian nyaris cedera atau KTD maka Komite Akreditasi Rumah Sakit (KARS) mengemukakan 6 sasaran keselamatan pasien (patient safety) sebagai syarat untuk diterapkan di semua rumah sakit yang diakreditasi oleh KARS. Penyusunan ini mengacu kepada nine life-saving Patient Safety Solutions dari WHO Patient safety (2007) yang juga digunakan oleh Komite Keselamatan Pasien Rumah sakit (KKPRS
PERSI) dan dari Joint Commission International (JCI). Enam sasaran tersebut yaitu: mengidentifikasi pasien dengan benar, meningkatkan komunikasi yang efektif, meningkatkan keamanan obat-obatan yang harus diwaspadai, memastikan lokasi pembedahan yang benar, prosedur yang benar, pembedahan pada pasien dengan benar, mengendalikan resiko infeksi dan pengurangan resiko jatuh (KARS, 2011).

Pelayanan keperawatan diberikan dengan berorientasi pada tujuan pelayanan keperawatan yang akan dicapai. Pencapaian tujuan pelayanan keperawatan di rumah sakit dipengaruhi oleh aktifitas pelayanan keperawatan yang diberikan kepada klien melalui penerapan asuhan keperawatan untuk pencapaian tujuan layanan kesehatan sesuai tugas, wewenang dan tanggung jawab serta mengacu pada standar profesi (Undang-undang No. 36 tahun 2009 pasal 24). Pelayanan kesehatan yang bermutu dan aman membutuhkan peran optimal dari setiap tenaga kesehatan termasuk perawat sebagai tenaga terdepan dalam sistem pelayanan.

Peran optimal perawat dalam pengembangan mutu pelayanan keperawatan telah berkembang dan mengarah pada tuntutan akan kompetensi yang adekuat untuk mendukung gerakan keselamatan pasien. Menurut Mitchell dalam Hughes (2008), perawat merupakan kunci dalam pengembangan mutu melalui keselamatan pasien. The Institute of Medicine (IOM) pada tahun 2000 mengemukakan dua peran perawat dalam keselamatan pasien yaitu memelihara keselamatan melalui transformasi lingkungan keperawatan yang lebih mendukung keselamatan pasien dan peran perawat dalam keselamatan pasien melalui penerapan standar keperawatan yang terkini.Sosialisasi program dan kebijakan mengenai keselamatan pasien dalam rangka 
membangun fondasi keselamatan pasien yang dibutuhkan telah diupayakan secara nasional oleh KPP-RS melalui road show di 12 kota besar yang dilanjutkan dengan workshop di beberapa rumah sakit di Indonesia. Namun diperlukan pendekatan sistemik dan peningkatan fondasi keselamatan pasien (Lumenta, 2008). Yates (2006) menyatakan bahwa fondasi dan pilar perawatan pasien secara aman terdiri atas teknologi, proses dan sumber daya manusia. Sehubungan dengan hal ini pula salah satu rekomendasi IOM adalah membangun program pelatihan secara interdisipliner. Despins, Scott dan Rouder (2010) dalam penelitiannya berpendapat bahwa pengembangan riset dalam bentuk intervensi mengenai keselamatan pasien seharusnya diarahkan untuk meningkatkan kemampuan deteksi oleh perawat mengenai tanda-tanda risiko cidera dan dapat meningkatkan keselamatan pasien dalam lingkungan pelayanan yang semakin kompleks.

Peningkatan pengetahuan merupakan dampak yang diharapkan dari adanya pelatihan. Marquis dan Huston (2006) menyatakan bahwa program pengembangan staf melalui pelatihan dan pendidikan merupakan program yang efektif untuk meningkatkan produktifitas perawat. Dukungan yang adequat dalam bentuk pelatihan profesional dan pengembangan pengetahuan merupakan salah satu upaya untuk menciptakan lingkungan kerja yang posistif bagi perawat agar asuhan yang aman dapat diberikan (ICN, 2007).

Pelatihan didefinisikan sebagai metode yang terorganisir untuk memastikan bahwa individu memiliki pengetahuan dan keterampilan tertentu dan individu memperoleh pengetahuan yang baik mengenai kewajiban dalam pekerjaannya. Pengetahuan tersebut dapat meningkatkan kemampuan afektif, motor dan kognitif sehingga akan diperoleh suatu peningkatan produktifitas atau hasil yang baik (Marquis \& Huston, 2006). Penelitian yang dilakukan oleh Hennessy, Hicks, Hilan dan Kawonal (2006) terhadap 524 perawat dari 5 provinsi di Indonesia yaitu Sulawesi Utara, Kalimantan Timur, Sumatera Utara, Jawa Barat dan DKI Jakarta menemukan bahwa seluruh responden secara signifikan menyatakan adanya kebutuhan untuk memperoleh pelatihan mengenai tugas dan pekerjaan yang harus dilakukan perawat. Penelitian ini juga secara nyata menemukan bahwa kebutuhan pelatihan lebih besar pada kelompok perawat yang bekerja dalam lingkup rumah sakit. Dalam lingkup keselamatan pasien, pengetahuan SDM (sumber daya manusia) di kesehatan termasuk perawat merupakan hal yang berhubungan dengan komitmen yang sangat diperlukan dalam upaya untuk membangun budaya keselamatan pasien (Cahyono, 2008).

Ada beberapa metode yang dapat di terapkan dalam memberikan pelatihan. Menurut Marquis \& Huston, (2006): Rivai \& Sagala (2009) metode yang dapat digunakan dalam pengembangan SDM berdasarkan teknik dan prinsip belajar yaitu: On the job training dan Off the job training. Off the job training terdiri dari ceramah kelas, case study, simulasi, praktek laboratorium, role playing dan behavior modeling.

RS Pekanbaru Medical Center merupakan salah satu RS swasta kelas B di Kota Pekanbaru memiliki 86 orang perawat yang tersebar di 7 ruangan yang meliputi Instalasi Rawat Inap, Instalasi Rawat Jalan, ICU, Instalasi Bedah, Instalasi Kamar Bersalin dan Instalasi Gawat Darurat. RS PMC telah memiliki Komite Keselamatan Pasien sebagai langkah awal upaya konstruktif dalam rangka penerapan kebijakan mengenai keselamatan pasien sekaligus sebagai antisipasi terhadap makin 
meningkatnya harapan pelanggan terhadap pelayanan yang bermutu. RS PMC mempunyai moto Pasien Menjadi Center sehingga RS PMC ini juga sangat mengedepankan patient safety dalam memberikan pelayanan.

Berdasarkan Survei Pendahuluan yang dilakukan di RS PMC pelaksanaan patient safety telah dimulai sejak tahun 2015 yang dimulai dengan pengenalan patient safety, pembuatan sistem kerja dan penyusunan tim KPRS. Wawancara terhadap tim KKP-RS RS PMC pada bulan Maret 2017 ditemukan bahwa tenaga keperawatan yang ada di Rumah Sakit PMC belum menempatkan pelaporan sebagai salah satu prioritas utama dalam mendukung penerapan tujuh langkah menuju keselamatan pasien yang telah dijadikan sebagai kebijakan. Belum adanya persepsi yang sama tentang pengisian format pelaporan insiden, pemilahan insiden yang belum begitu tepat, dan adanya perasaan takut disalahkan jika melaporkan suatu insiden teridentifikasi sebagai kendala yang ditemukan oleh Tim KKP-RS dalam hubungannya dengan keterlibatan perawat dalam penerapan program keselamatan pasien. Perawat sering kali harus dimotivasi untuk melaporkan insiden yang mereka temukan dan proses pelaporan yang seringkali hanya lisan juga menyulitkan dalam pemantauan terhadap insiden di RS PMC. Belum optimalnya nilai-nilai kesadaran dalam membangun budaya keselamatan pasien yang berhubungan dengan peran perawat melalui peningkatan kompetensi dalam mendukung pelaksanaan program keselamatan pasien yang harus terus menerus diingatkan juga merupakan kondisi yang dirasakan harus dibenahi. Atas pertimbangan tersebut peneliti tertarik untuk meneliti mengenai " Pengaruh Pelatihan Keselamatan Pasien Dengan Metode Ceramah Terhadap Pemahaman Perawat
Mengenai Penerapan Sasaran Keselamatan Pasien Di RS PMC Pekanbaru"

\section{METODOLOGI PENELITIAN}

Metode penelitian yang digunakan metode kuantitatif dengan one grup. Penelitian ini di laksanakan di Rumah Sakit Pekanbaru Medical Center dengan sampel penelitian adalah perawat yang bertugas di RS tersebut yaitu sebanyak 30 orang sesuai sesuai kriteria inklusi.

\section{HASIL DAN PEMBAHASAN}

Tabel

Pemahaman perawat tentang penerapan keselamatan pasien pada kelompok ceramah sebelum dan setelah diberikan pelatihan

\begin{tabular}{|c|c|c|c|c|c|}
\hline \multirow[t]{2}{*}{ Variabel } & \multicolumn{2}{|c|}{ Pre-test } & \multicolumn{2}{|c|}{ Post-test } & \multirow{2}{*}{$\begin{array}{c}\mathrm{P} \\
\text { value }\end{array}$} \\
\hline & Mean & SD & Mean & SD & \\
\hline $\begin{array}{l}\text { Pemahaman } \\
\text { Perawat } \\
\text { mengenai } \\
\text { penerapan } \\
\text { keselamatan } \\
\text { pasien }\end{array}$ & 52,83 & 7,742 & 67,47 & 8,320 & 0,000 \\
\hline
\end{tabular}

Berdasarkan uji statistik $t$ dependent pada table diatas didapatkan mean nilai pemahaman perawat tentang budaya keselamatan pasien sebelum dilakukan pelatihan dengan metode ceramah adalah 52,83 dengan standar deviasi 7,742. Mean nilai pemahaman perawat tentang penerapan keselamatan pasien setelah dilakukan pelatihan dengan metode ceramah adalah 67,47 dengan standar deviasi 8,320.

Hasil uji $t$ dependent dimana $p$ value $=0.000$ lebih kecil daripada nilai alpha $(p<$ $0,05)$ didapatkan adanya pengaruh yang signifikan antara mean nilai pemahaman perawat tentang penerapan keselamatan 
pasien sebelum dan setelah dilakukan pelatihan dengan metode ceramah.

Penelitian ini sejalan dengan penelitian yang dilakukan oleh Dauer, Kelvin, Horan, dan Germain (2006) mengenai efektifitas pelatihan yang dilakukan terhadap sekelompok perawat onkologi yang memberikan terapi radiasi menemukan bahwa ada perbedaan signifikan pengetahuan kognitif yang diukur antara pre test dan post test serta adanya peningkatan sikap yang positif pada 5 dari 9 area sikap yang dievaluasi. Hasil penelitian ini juga sesuai dengan penelitian yang dilakukan Kirana (2007) yang menemukan bahwa ada perbedaan kemampuan kognitif perawat secara signifikan pada kelompok intervensi sebelum dan setelah diberikan pelatihan dengan $p$ value 0,000 .

Hasil penelitian pada kelompok dengan metode ceramah yang menunjukkan ada perbedaan pemahaman sebelum dan setelah pelatihan membuktikan bahwa pelatihan dapat mempengaruhi pemahaman perawat pelaksana secara positif. Perbedaan pemahaman sebelum dan setelah pelatihan yang diberikan terhadap perawat pelaksana pada kelompok dengan metode ceramah mengenai penerapan keselamatan pasien dalam pelayanan keperawatan merupakan peningkatan hasil yang diharapkan dari pemberian intervensi berupa pelatihan. Hal ini sejalan dengan pendapat Rivai dan Sagala (2009) yang menyatakan bahwa jika kemampuan peserta pelatihan meningkat secara signifikan, artinya program pelatihan secara aktual menyebabkan terjadinya perbedaan kemampuan. Program pelatihan dapat dikatakan berhasil apabila peningkatan kemampuan dapat memenuhi kriteria evaluasi dan dapat ditransfer ke pekerjaan serta mengakibatkan perubahan sikap yang dapat diukur dengan meningkatkan performance pekerjaan.
Evaluasi dampak program pelatihan yang diberikan perlu diiringi dengan suatu pelatihan yang berkesinambungan, terprogram dan terencana sesuai dengan peningkatan kebutuhan perawat atas hal spesifik yang menjadi tuntutan kinerja perawat dalam menerapkan keselamatan pasien. Alokasi waktu yang tidak cukup panjang untuk pemberian intervensi berupa pelatihan dalam penelitian ini perlu dipertimbangkan sebagai faktor yang berdampak pada belum optimalnya pencapaian pemahaman perawat pelaksana pada kelompok eksperimen.

\section{SIMPULAN}

Berdasarkan landasan teori dan didukung oleh analisa dan hasil uji statistic, maka dapat di simpulkan bahwa mean nilai pemahaman perawat tentang budaya keselamatan pasien sebelum dilakukan pelatihan dengan metode ceramah adalah 52,83 dengan standar deviasi 7,742. Mean nilai pemahaman perawat tentang penerapan keselamatan pasien setelah dilakukan pelatihan dengan metode ceramah adalah 67,47 dengan standar deviasi 8,320. Hasil uji $t$ dependent dimana $p$ value $=0.000$ lebih kecil daripada nilai alpha $(p<0,05)$ didapatkan adanya pengaruh yang signifikan antara mean nilai pemahaman perawat tentang penerapan keselamatan pasien sebelum dan setelah dilakukan pelatihan dengan metode ceramah.

\section{UCAPAN TERIMAKASIH}

Peneliti mengucapakan teriama kasih kepada Kemenristek Dikti yang telah mendanai Penelitian ini pada Program Dana Hibah Penelitian Dosen Pemula Kemenristek Dikti Pendanaan tahun 2018. 


\section{DAFTAR PUSTAKA}

Cahyono, J.B.S.B. (2008). Membangun budaya keselamatan pasien dalampraktik kedokteran. Yogyakarta: Penerbit Kanisius

Canadian Nurses Association. (2009). Position statement patient safety. Ottawa: The Author. http://www.cna- a i i c . c a / c n a / d oc u ments/pdf/public a tions/PS102_Patient_S afety_e.pdf

Considine, J. (2005). The role of nurses in preventing adverse events related to respiratory dysfunction: Literature review. Journal of Advanced Nursing, 49 (6), 624-633.

Dauer, L.T., Kelvin, J.F., Horan, C.L., \& Germain, J.S. (2006). Evaluating the effectiveness of a radiation safety training intervention for oncology nurses: A pretestintervention-posttest study. $B M C$ Medical Education, 6 (32), 472482.

http://www.ncbi.nlm.nih.gov/pmc/a rticles/PMC1513562/pdf/1472-

6920-6- 32.pdf

Depkes. (2008). Pedoman indikator mutu pelayanan keperawatan klinik di sarana kesehatan. Jakarta: The Author.

Depkes \& KKP-RS. (2008). Panduan nasional keselamatan pasien rumah sakit. (Edisi 2). Jakarta: The Author.

(2008). Pedoman pelaporan insiden keselamatan pasien (IKP). (Edisi 2). Jakarta: The Author.

Despins, L.A., Scott, C.J., \& Rouder, J.N. (2010). Detection of patient risk by nurses: a theoretical framework. Journal of Advanced Nursing, 66 (2), 465-474. http://www3.interscience.wiley.co $\mathrm{m} /$ journal/123247860

Flynn, E. (2004). Crossing the quality chasm: a new system for 21th century. USA: National Academies Press.

http://cart.nap.edu/cart/pdfaccess.cg i?\&record_id=10027

Gillies, D.A. (1994). Nursing management: a sistem approach. (3rd ed.) Phyladelphia: WB. Saunders Company

Ginsburg, L., Norton, P.G., Casebeer, A., \& Lewis., S. (2005). An educational intervention to enhance nurse leader's perception of patient safety culture. Health Research and Educational Trust, 40 (4), 9971020.

http://www.ncbi.nlm.nih.gov/pmc/a rticles/PMC1361187/pdf/hesr_0040 1.pd $\mathrm{f}$,

Hamric, A.B., Spross, J.A. \& Hanson, C.M. (2009). Advanced practice nursing: An integrative approach. USA: Elsevier.

Hennessy, D., Hiscks, C., Hilan, A., \& Kawonal, Y. (2006). The training and development needs of nurses in Indonesia: Paper 3 of 3. Human Resources for Health, 4 (10), 165179. http://www.ncbi.nlm.nih.gov/pmc/a 
rticles/PMC1524804/pdf/1478-44914- 10.pdf

Henriksen, K., Joseph, A., \& Zayas-Caban, T. (2009). The human factors of home health care: a conceptual model for examining safety andquality concerns. Journal of Patient Safety, 5 (4), http://journals.lww.com/journalpati entsafety/Abstract/2009/12000/The _Human_Factors_of_Home_Health _Care_A.7.aspx

Huber, D.L. (2006). Leadership and nursing management. (3rd ed.). Philadelphia: Saunders Elsevier.

Hughes, R.G (2008). Patient safety and quality: an evidence-based handbook for nurses. Rockville MD: Agency for Healthcare Research and Quality Publications.http://www.ahrq.gov/ QUAL/nurseshdbk/

International Council of Nurse \& World Health Organization. (2007). Islamabad declaration on strengthening nursing and midwifery. http://www.icn.ch

(2007). International nursing day, positive practice environment: quality workplaces = quality patient care. Information and action tool kit. Geneva: The Author. http://www.icn.ch

(2009). International nursing days, delivering quality, serving qualities: nurses leading care innovations. Geneva: The Author. Mei 05, 2009. http://www.icn.ch
Kohn, L.T., Corrigan, J.M., \& Donaldson, M.S. (2000). To err is human: building a safer health sistem. Washington DC: National Academies Press. Desember 20, 2009.

http://www.nap.edu/openbook.php? isbn $=0309068371$.

Lumenta, N.A (2008). State of the art patient safety. Disampaikan pada Workshop Keselamatan Pasien dan Manajemen Resiko Klinis di RSAB Harapan Kita pada tanggal 1-3 April 2008. Jakarta: Tidak Dipublikasikan.

Mangkuprawira, T.S. (2008). Merubah perilaku karyawan. http://ronawajah.wordpress.com/20 08/02/15/merubah-perilakukaryawan/

Marquis, B.L. \& Huston, C.J. (2006). Leadership roles and management functions in nursing: therory and application. (5th Ed.). Philadelphia: Lippincott Williams \& Wilkins.

Morrison, J.E. (1991). Training for performance: principles of applied human learning. USA: John Wiley \& Sons Inc.

Persatuan Perawat Nasional Indonesia. (2010). Standar profesi dan kode etik perawat indonesia. Jakarta: The Author.

Reed, S.K. (2000). Cognition: theory and applications. (5th ed.) USA: Wadsworth Thomson Learning.

Rivai, V. \& Sagala, E.J. (2009). Manajemen Sumber Daya Manusia untuk 
Perusahaan: Dari Teori ke Praktik. Edisi ke-2. Jakarta: Rajawali Pers.

Schoonhoven, L., Grobbee, D.E., Bousema, M.T., dan Buskens, E. (2005). Predicting pressure ulcers: cases missed using in a new clinical prediction rule. Journal of Advanced Nursing, 49 (1), 16-22.

Thite, M. (2004). Managing people in the new economy: targeted HRpractices that persuade people to unlock their knowledge. New Delhi: Sage Publications

Undang-Undang Republik Indonesia Nomor 36 tahun 2009 tentang Kesehatan.

Undang-Undang Republik Indonesia Nomor 44 Tahun 2009 tentang Rumah Sakit.

WHO. (2007). Nine Life Saving Patient Safety Solution. Januari 03, 2010. http://www.who.int

Wibowo. (2007). Manajemen kinerja. (Edisi 1). Jakarta: PT Raja Grafindo Persada.

Yahya, A.A. (2006). Konsep dan program patient safety. Disampaikan pada Konvensi Nasional Mutu RS ke VI. Bandung. http://www.pdpersi.co.id 